\title{
Rechtsbescherming tegen de cumulatie van privaatrechtelijke en strafrechtelijke gebiedsverboden
}

\section{Benny van der Vorm*}

De aanpak van misdaad is niet uitsluitend een taak van het strafrecht, ook het bestuursrecht en het privaatrecht worden ingezet om te voorkomen dat misdaad of overlastgevend gedrag plaatsvindt. Dit wordt aangeduid als de integrale aanpak. Inmiddels wordt de integrale aanpak toegepast op verschillende vormen van misdaad. Een bekend voorbeeld hiervan is de integrale aanpak van de ondermijnende criminaliteit (Tops \& Schilders 2016). Een belangrijk kenmerk van de integrale aanpak is dat zowel strafrechtelijk als bestuursrechtelijk en privaatrechtelijk kan worden gereageerd. Het is echter van belang om de rechtsbeschermende functie van het recht niet uit het oog te verlie-

zen. 't Hart en Foqué hebben reeds lang geleden erop gewezen dat het recht niet uitsluitend een instrumentele functie toekomt, maar eveneens rechtsbescherming biedt ('t Hart \& Foqué 1990). De toepassing van de integrale aanpak mag er niet toe leiden dat de betrokkene dubbel wordt bestraft; er dient met andere woorden rechtsbescherming te worden geboden tegen cumulatie van bestraffende sancties. Zo is cumulatie tussen een oplegging van een bestuurlijke boete en een strafrechtelijke vervolging wegens hetzelfde feit niet mogelijk, omdat beide sancties bestraffend van aard zijn. Dit ligt anders ten aanzien van de bestuurlijke gebiedsverboden. De oplegging van bestuurlijke gebiedsverboden kunnen bezwaarlijk worden aangemerkt als een 'criminal charge', waardoor de mate van rechtsbescherming afwijkt van de procedure tot oplegging van strafrechtelijke gebiedsverboden (Van der Vorm 2017). Samenloop tussen een bestuurlijk en een strafrechtelijk gebiedsverbod is evenwel niet - altijd - mogelijk, zo blijkt uit

* Mr. dr. drs. B. van der Vorm is universitair docent straf(proces)recht en verbonden aan het Willem Pompe Instituut en het Montaigne Centrum voor Conflictoplossing en Geschillenbeslechting van de Universiteit Utrecht. 
artikel 172a lid 5 Gemeentewet. De materie omtrent samenloop van bestuurlijke en strafrechtelijke gebiedsverboden lijkt redelijk te zijn uitgekristalliseerd, maar geldt dit ook voor de cumulatie tussen privaatrechtelijke en strafrechtelijke gebiedsverboden? Er is gewezen op mogelijke problematische aspecten van de samenloop tussen privaatrechtelijke en strafrechtelijke gebiedsverboden (Van Rooij 2017). Zo blijkt nog enige onduidelijkheid te bestaan over de al dan niet bestraffende aard van een privaatrechtelijk gebiedsverbod. Deze kwestie wordt in dit artikel nader onderzocht aan de hand van twee soorten privaatrechtelijke gebiedsverboden, namelijk het stadionverbod en de collectieve horecaontzegging.

In deze bijdrage staat de volgende onderzoeksvraag centraal: 'In hoeverre staat de oplegging van een privaatrechtelijk stadionverbod en een collectieve horecaontzegging een oplegging van een strafrechtelijk gebiedsverbod in de weg?' Teneinde deze onderzoeksvraag te kunnen beantwoorden wordt ten eerste aandacht besteed aan de inhoud van het privaatrechtelijke stadionverbod en de collectieve horecaontzegging. Ten tweede wordt aan de hand van jurisprudentie onderzocht of deze privaatrechtelijke gebiedsverboden een bestraffend element in zich dragen. Ten derde wordt aandacht besteed aan de kwestie van cumulatie van privaatrechtelijke en strafrechtelijke gebiedsverboden. Er wordt afgesloten met een conclusie.

\section{De inhoud van de toepasselijke privaatrechtelijke gebiedsverboden}

\section{De inhoud van het stadionverbod}

Ten aanzien van de aanpak van voetbalgeweld is een belangrijke rol weggelegd voor het privaatrecht. Dit is niet verwonderlijk, omdat de aard van voetbalgeweld is terug te voeren tot een contract. Hiermee wordt bedoeld dat door middel van de aanschaf van een voetbalkaartje een contractuele relatie ontstaat tussen de bezoeker van de voetbalwedstrijd en de KNVB. Als de contractuele verplichtingen worden geschonden, kan hierop worden gereageerd door middel van het opleggen van sancties. De KNVB heeft in de Standaardvoorwaarden opgenomen dat ten aanzien van voetbalgeweld twee sancties mogelijk zijn: uitsluiting van het bijwonen van toekomstige wedstrijden (het stadionverbod) en de verplichting tot betaling van een geldboete (Van 
Rooij e.a. 2016). Een belangrijke bepaling in dit verband is artikel 10.2 van de Standaardvoorwaarden. Op grond van deze bepaling kan de KNVB een landelijk stadionverbod opleggen aan eenieder die heeft gehandeld in strijd met de Standaardvoorwaarden en/of een strafbaar feit heeft begaan en/of ten aanzien van wie een vermoeden bestaat dat deze zich schuldig heeft gemaakt aan voetbalgerelateerd wangedrag, en/of zich zodanig heeft gedragen dat daardoor het aanzien en/of het belang van het voetbal wordt geschaad.

In artikel 8 van de Standaardvoorwaarden en in de Richtlijn Termijn Stadionverbod is neergelegd wanneer sprake is van handelen in strijd met de Standaardvoorwaarden. Uit deze richtlijn blijkt dat indien de Wet op de identificatieplicht in het stadion wordt geschonden, een stadionverbod kan worden opgelegd voor de duur van drie maanden, waarvan de eerste keer voorwaardelijk is. Dit is, wat de duur betreft, de lichtste vorm van een stadionverbod. Een stadionverbod kan 240 maanden duren, indien sprake is van deelneming aan een aanval en/ of vechterij met de dood ten gevolge. Als sprake is van recidive van de meest ernstige gedragingen als bedoeld in de richtlijn, waarvoor in beginsel een termijn van 240 maanden geldt, kan een levenslang stadionverbod worden opgelegd. Dit is ter beoordeling van de KNVB. Het stadionverbod kan worden aangemerkt als een civiele sanctie, die wordt opgelegd door de KNVB (Brouwer \& Jacobs 2012). ${ }^{1}$

\section{De inhoud van de collectieve horecaontzegging}

De collectieve horecaontzegging is een uitvloeisel van de publiek-private samenwerking op grond van opgestelde protocollen Collectieve horecaontzegging. Een persoon die geweld, diefstal, drugshandel of vernieling pleegt in of rond een uitgaansgelegenheid kan voor bepaalde tijd een ontzegging krijgen van de toegang bij alle aangesloten horecagelegenheden. Hieraan zijn bepaalde voorwaarden verbonden, zoals het uitwisselen van persoonsgegevens tussen horeca en politie. Wanneer een persoon met ontzegging toch de horeca binnengaat, is er sprake van lokaalvredebreuk. De collectieve horecaontzegging wordt vooral geschikt geacht voor de notoire overlastgever, maar in beginsel kan deze worden opgelegd aan iedereen die (herhaaldelijk) 
strafbare feiten pleegt of de Algemene Plaatselijke Verordening (APV) overtreedt in de horeca of op het terras (privédomein).

Uit het KHN Modelprotocol CHO uit 2010 blijkt dat de duur van de collectieve horecaontzegging samenhangt met de zwaarte van het strafbare feit. Een collectieve horecaontzegging kan worden opgelegd voor de duur van drie maanden, indien er softdrugs van meer dan vijf gram (de gedoogde hoeveelheid) worden aangetroffen, sprake is van ergerlijk lastigvallen van horecaondernemer/-personeel of klant (ordeverstoring APV) of de persoon in kwestie betrokken is bij een vechtpartij in de horecagelegenheid (ordeverstoring APV). Een collectieve horecaontzegging kan maximaal voor vijf jaren worden opgelegd. Er dient dan sprake te zijn van een zware mishandeling van de klant, de horecaondernemer of -personeel door de persoon in kwestie, een vuurwapen dat door deze persoon is gebruikt of meer dan twee schriftelijke waarschuwingen, en er dient meer dan één individuele horecaontzegging te zijn opgelegd.

In veel gevallen beslissen de portiers over de oplegging van een collectieve horecaontzegging en over het naleven van eerder opgelegde collectieve horecaontzeggingen. Zij dienen dan wel contact op te nemen met de politie. Vervolgens verstrekt de politie de gegevens over de overlastpleger aan de horecaondernemer. De politie en horecaondernemer bepalen gezamenlijk de duur van de collectieve horecaontzegging. De ontzegging wordt overhandigd of aangetekend verstuurd naar de overlastpleger. Indien deze persoon toch een aangesloten horecagelegenheid betreedt, wordt aangifte gedaan wegens overtreding van artikel 138 van het Wetboek van Strafrecht (Sr; lokaalvredebreuk) (Schuilenburg \& Van Steden 2010). Wanneer aan de verdachte schriftelijk de toegang tot de desbetreffende horecagelegenheden is ontzegd, brengt de enkele omstandigheid dat de verdachte feitelijk in die gelegenheden is binnengelaten, niet mee dat van 'wederrechtelijk binnendringen' geen sprake kan zijn, zo blijkt uit jurisprudentie van de Hoge Raad. ${ }^{2}$ Voorts kan de oplegging van een collectieve horecaontzegging niet worden aangemerkt als een besluit in de zin van de Algemene wet bestuursrecht (Awb). ${ }^{3}$ 


\title{
Het stadionverbod en de collectieve horecaontzegging als bestraffende sanctie?
}

\author{
De 'verhoogde' rechtsbescherming van de 'criminal charge'
}

Volgens Schuilenburg en Van Steden heeft de collectieve horecaontzegging kenmerken van een straf en zou deze ontzegging in beginsel ook door de strafrechter opgelegd kunnen worden (Schuilenburg \& Van Steden 2014). Inderdaad, de strafrechter kan op grond van artikel $14 \mathrm{c} \mathrm{Sr}$ als bijzondere voorwaarde bij een voorwaardelijke straf een gebiedsverbod opleggen. Ook kan de strafrechter op grond van artikel $38 \mathrm{v}$ Sr een gebiedsverbod bij wijze van maatregel opleggen. Er dient dan echter wel een vervolging te zijn ingesteld tegen de verdachte. Zonder tussenkomst van de rechter kan de officier van justitie een verdachte een zogeheten gedragsaanwijzing opleggen, die kan inhouden dat de verdachte een gebiedsverbod wordt opgelegd (art. 509hh van het Wetboek van Strafvordering (Sv)). Genoemde strafrechtelijke gebiedsverboden kunnen uitsluitend worden opgelegd indien sprake is van een verdachte, terwijl een privaatrechtelijk gebiedsverbod kan worden opgelegd wegens het niet naleven van de huisregels.

Hoewel het mogelijk is om privaatrechtelijke gebiedsverboden op te leggen, betekent dit niet dat het stadionverbod en de collectieve horecaontzegging kunnen worden aangemerkt als bestraffende sancties.

De vraag naar de kwalificatie van een 'criminal charge' is relevant, omdat in dergelijke gevallen de 'verhoogde' rechtsbescherming van artikel 6 lid 2 en 3 van het Europees Verdrag tot bescherming van de rechten van de mens en de fundamentele vrijheden (EVRM) van toepassing is op de procedure. Indien sprake is van een 'criminal charge' dient sprake te zijn van toegang tot een onpartijdige en onafhankelijke rechter, een eerlijke en openbare behandeling van de zaak binnen een redelijke termijn en 'full jurisdiction'. Bovendien moet er sprake zijn van een evenredigheidstoetsing ten aanzien van de sanctie en gelden de onschuldpresumptie, het zwijgrecht, het nemo tenetur-beginsel en het recht op bijstand van een raadsman bij het eerste verhoor.

\section{Het stadionverbod als 'criminal charge'?}

De Hoge Raad heeft zich uitgesproken over de rechtmatigheid van een opgelegd privaatrechtelijk stadionverbod en een privaatrechtelijke 
geldboete in combinatie met een strafrechtelijke vervolging. In die zaak heeft het Gerechtshof Amsterdam de verdachte op 27 januari 2015 voor het openlijk in vereniging geweld plegen tegen personen veroordeeld tot een gevangenisstraf van twee maanden, waarvan een maand voorwaardelijk. Ten aanzien van hetzelfde feit is bovendien door de KNVB aan de verdachte een driejarig stadionverbod opgelegd in combinatie met een privaatrechtelijke geldboete van $€ 450$. Volgens de verdediging dienen het opgelegde stadionverbod en de geldboete te worden aangemerkt als een 'criminal charge', waardoor de strafrechtelijke vervolging van de verdachte door het Openbaar Ministerie in strijd is met het verbod van dubbele vervolging (ne bis in idem-beginsel). De Hoge Raad overweegt in rechtsoverweging 2.3.1 als volgt:

'In cassatie kan ervan worden uitgegaan dat het opleggen van een stadionverbod door de KNVB en het verbeuren van een geldboete aan de KNVB steunen op de standaardvoorwaarden die van toepassing zijn op de bij de koop van een toegangs- of seizoenskaart gesloten civielrechtelijke overeenkomst. Het opleggen van een stadionverbod en/of het verbeuren van de geldboete zijn slechts mogelijk ten aanzien van de koper van een toegangs- of seizoenskaart en louter ter zake van het - kort gezegd - in het kader van een voetbalwedstrijd niet-naleven van die voorwaarden, ook al kan de verdenking van het begaan zijn van een strafbaar feit wel de aanleiding vormen voor het opleggen aan hem van een stadionverbod en/of het verbeuren door hem van een geldboete. Voorts wordt een persoon aan wie door de KNVB een stadionverbod is opgelegd slechts beperkt in zijn bewegingsvrijheid gehinderd en is aan het verbeuren van een geldboete rechtens geen vervangende hechtenis verbonden. Gelet hierop kan de toepassing van deze maatregelen door de KNVB niet worden aangemerkt als een "criminal charge" als bedoeld in artikel 6 EVRM (vgl. de criteria genoemd in EHRM 8 juni 1976, nr. 5370/72, Engel tegen Nederland, NJ 1978/223).'4

Bij deze overweging zijn vraagtekens gezet door de annotatoren Wierenga en Brouwer. De annotatoren geven terecht aan dat het stadionverbod en de privaatrechtelijke geldboete moeten worden aangemerkt als puur privaatrechtelijke sancties. Ten aanzien van de vraag in hoeverre een sanctie als een 'criminal charge' wordt aangemerkt, is de kwalificatie in het nationale recht niet van doorslaggevend belang. Kij- 
kend naar de combinatie van het stadionverbod met de geldboete zijn Wierenga en Brouwer van mening dat er aan de geldboete wel degelijk een punitief aspect zit. Ook wijzen zij erop dat de KNVB de privaatrechtelijke sancties heeft opgelegd naar aanleiding van informatie van het Openbaar Ministerie. De annotatoren zijn van mening dat de geldboete moet worden aangemerkt als een strafsanctie (Wierenga \& Brouwer 2014). Deze privaatrechtelijke geldboete wordt opgevat als een 'punitive damage'. De term 'punitive damage' is een veelgebruikt synoniem voor de privaatrechtelijke geldboete (Bolt \& Lensing 1993). Door verschillende auteurs is betoogd dat ten aanzien van 'punitive damages' de 'verhoogde' strafrechtelijke waarborgen eveneens van toepassing zouden moeten zijn (Adriaanse e.a. 2008). Er lijken sterke argumenten te bestaan om 'punitive damages' aan te merken als een 'criminal charge' (Giesen 2015).

Kan het stadionverbod eveneens worden aangemerkt als een 'punitive damage'? Het antwoord op deze vraag luidt naar mijn mening ontkennend, omdat het stadionverbod in tegenstelling tot de geldboete geen financieel aspect omvat. Zou het stadionverbod kunnen worden aangemerkt als een 'criminal charge'? Deze vraag dient te worden beantwoord aan de hand van de 'Engel-criteria'. ${ }^{5}$ Deze criteria luiden als volgt:

a. Is de handhaving van de overtreden norm naar geldend nationaal recht als strafrechtelijk aan te merken?

b. Wat is de aard van de verweten handeling?

c. Wat zijn de aard en zwaarte van de sanctie die met de overtreding wordt geriskeerd?

Ten aanzien van het a-criterium moet worden vastgesteld dat de handhaving van de overtreden norm privaatrechtelijk van aard is. Dit betekent echter geenszins dat dan ook geen sprake is van een 'criminal charge'. Om 'Etikettenschwindel' te voorkomen zijn het b-criterium en het c-criterium van meer gewicht.

Met betrekking tot het b-criterium kan worden vastgesteld dat de aard van de verweten handeling is gelegen in gepleegde strafbare feiten. In casu is het stadionverbod opgelegd naar aanleiding van strafbare feiten, maar is de kring van de normadressaten tot wie de KNVB zich richt beperkt. Indien de overtreden regel immers is gericht tot alle burgers, wordt de overtreding veelal op basis van het normadressaat-cri- 
terium door het Europees Hof voor de Rechten van de Mens (EHRM) als 'criminal' van aard beschouwd; is de overtreden regel gericht tot de leden van een bepaalde groep en geldt deze regel in een bepaalde omgeving of sfeer, dan is een overtreding van deze regel niet 'criminal' (Albers 2002). Nu de kring van normadressaten beperkt is, is dit een indicatie dat het stadionverbod niet dient te worden aangemerkt als een 'criminal charge'.

Het derde en laatste criterium is de aard en de zwaarte van de sanctie. Wierenga en Brouwer merken in hun annotatie op dat het stadionverbod het best kan worden aangemerkt als een privaatrechtelijke herstelsanctie, waarmee wordt beoogd om herhaling van ongewenst gedrag te voorkomen. Het feit dat de meeste herstelsancties van een geheel andere aard zijn dan een verbanning uit het stadion maakt dit niet anders. Bestraffing is met andere woorden niet beoogd. De toepassing van de Engel-criteria leidt tot de conclusie dat het stadionverbod niet kan worden aangemerkt als een 'criminal charge'.

Van Rooij geeft aan dat een stadionverbod ook (deels) punitief van aard kan zijn, omdat uit de Richtlijn Termijn Stadionverbod blijkt dat de ernst van het feit de duur van het stadionverbod bepaalt en niet de dreiging die van een persoon uitgaat. Ook kunnen onder omstandigheden stadionverboden zeer langdurig zijn, waardoor sprake zou zijn van een punitief karakter. In de kern is haar standpunt dat stadionverboden vooral herstelsancties zijn, maar dat wanneer de duur van het stadionverbod niet meer in redelijke verhouding staat met de dreiging die uitgaat van een bepaald persoon en het stadionverbod is bedoeld om de afkeuring duidelijk te maken, het verbod ook bestraffend is (Van Rooij 2017). Naar mijn mening laat een toetsing aan de Engel-criteria zien dat een stadionverbod - zoals het thans door de KNVB wordt opgelegd - niet dient te worden opgevat als een 'criminal charge'. Het stadionverbod wordt immers niet opgelegd om leed toe te voegen, maar om herhaling van ongewenst gedrag te voorkomen. Een lange duur van het stadionverbod maakt dat het verbod ingrijpend(er) wordt, maar alles overziend is dit onvoldoende om te kunnen spreken van een 'criminal charge'.

\section{De collectieve horecaontzegging als 'criminal charge'?}

Net zoals het geval is bij het stadionverbod komt het in de praktijk voor dat naast de oplegging van een collectieve horecaontzegging 
- wegens hetzelfde feit - een strafrechtelijke vervolging wordt gestart. Uit een zaak in hoger beroep blijkt dat de verdachte wordt vervolgd ter zake van openlijke geweldpleging en mishandeling. Daarnaast wordt hij eveneens vervolgd voor bedreiging met geweld. Ter terechtzitting wordt in hoger beroep betoogd dat het Openbaar Ministerie niet-ontvankelijk dient te worden verklaard in de strafvervolging, aangezien de vervolging in strijd is met artikel $68 \mathrm{Sr}$, artikel 50 van het Handvest van de Grondrechten van de Europese Unie en artikel 4 van het Zevende Protocol bij het EVRM. Daartoe is aangevoerd dat aan de verdachte reeds een collectief horecaverbod is opgelegd, hetgeen moet worden aangemerkt als een 'criminal charge' in de zin van artikel 6 EVRM. Er is een collectieve horecaontzegging opgelegd voor de duur van twee jaren wegens de feiten waarvoor de verdachte wordt vervolgd. Het hof overweegt in rechtsoverweging C.3 als volgt:

'Gelet op het voorgaande is het hof van oordeel dat het onderhavige lokaalverbod een puur civielrechtelijke maatregel betreft. Naar het oordeel van het hof wordt een persoon aan wie een dergelijk lokaalverbod wordt opgelegd bovendien slechts beperkt in zijn bewegingsvrijheid gehinderd. Uit dit alles trekt het hof de conclusie dat, gelet op de juridische kwalificatie van het lokaalverbod en de aard en de zwaarte van de sanctie, de oplegging van het lokaalverbod door de horecaondernemers van Sittard en Geleen niet kan worden aangemerkt als een "criminal charge" als bedoeld in artikel 6 EVRM. Het openbaar ministerie verliest derhalve niet het recht tot strafvervolging van de verdachte door de enkele omstandigheid dat in verband met de ten laste gelegde feiten een lokaalverbod is opgelegd.' ${ }^{6}$

Door het hof wordt er eveneens op gewezen dat de rol van de politie slechts ondersteunend is en dat de collectieve horecaontzegging wordt opgelegd door de horecaondernemers. Het opleggen van een collectieve horecaontzegging kan volgens het hof dus niet worden aangemerkt als een 'criminal charge'. De belangrijkste reden die wordt aangedragen door het hof lijkt mij te zijn gelegen in het feit dat dit verbod een privaatrechtelijke sanctie is. Over de andere Engel-criteria laat het hof zich oppervlakkig uit.

In een vergelijkbare zaak is aan de verdachte eveneens een collectieve horecaontzegging opgelegd voor de duur van twee jaren wegens

6 Hof 's-Hertogenbosch 24 april 2016, ECLI:NL:GHSHE:2016:1675. 
geweld en bedreiging met geweld. De collectieve horecaontzegging wordt door de betrokkene overtreden, waardoor deze persoon wordt vervolgd wegens huisvredebreuk. Volgens de verdediging dient het Openbaar Ministerie niet-ontvankelijk te worden verklaard in de vervolging, onder andere vanwege het feit dat dit verbod ook een bestraffend karakter heeft. Het Gerechtshof 's-Hertogenbosch overweegt in rechtsoverweging E.2 als volgt over het rechtskarakter van de collectieve horecaontzegging:

'Uit hetgeen onder $\mathrm{A}$ is vermeld volgt dat de collectieve horecaontzegging is opgelegd door de horecaondernemers van Sittard en Geleen. De ontzegging is een waarschuwing van de horecaondernemers aan de verdachte dat hij, indien hij een van de horecagelegenheden betreedt die zijn genoemd op de website, zich aldaar wederrechtelijk bevindt en dat aangifte wordt gedaan van huisvredebreuk. Er is daarbij sprake van een wilsuiting van een private partij jegens een andere private partij. Het hof is daarom van oordeel dat de collectieve horecavoorziening civielrechtelijk van aard is (...) Uit dit alles trekt het hof de conclusie dat, gelet op de juridische kwalificatie van de collectieve horecaontzegging en de aard en de zwaarte van de sanctie, de oplegging van de collectieve horecaontzegging door de horecaondernemers van Sittard en Geleen niet kan worden aangemerkt als een "criminal charge" als bedoeld in artikel 6 van het EVRM. Aldus is het rechtskarakter van de collectieve horecaontzegging niet strafrechtelijk van aard. ${ }^{7}$

Uit deze jurisprudentie blijkt dat de oplegging van een collectieve horecaontzegging niet wordt aangemerkt als een 'criminal charge'. Toetsing aan de Engel-criteria lijkt inderdaad in die richting te wijzen. Hoewel handhaving van de norm privaatrechtelijk van aard is (a-criterium), betekent dit niet dat daarom geen sprake is van een 'criminal charge'. Net zoals het geval is met de oplegging van een stadionverbod kan met betrekking tot het b-criterium worden vastgesteld dat de aard van de verweten handeling is gelegen in gepleegde strafbare feiten. De collectieve horecaontzegging wordt opgelegd naar aanleiding van strafbare feiten, maar de kring van de adressaten tot wie de horecaondernemers zich richten, is beperkt. Dit laatste gegeven is een indicatie dat de collectieve horecaontzegging niet dient te worden 
aangemerkt als een 'criminal charge'. Het c-criterium is de aard en de zwaarte van de sanctie. De collectieve horecaontzegging dient te worden aangemerkt als een privaatrechtelijke herstelsanctie, waarmee wordt beoogd om herhaling van ongewenst gedrag in de aangesloten horecagelegenheden te voorkomen. Bestraffing is met andere woorden niet beoogd. De toepassing van de Engel-criteria leidt daarom tot de conclusie dat het collectieve horecaverbod niet kan worden aangemerkt als een 'criminal charge'.

\section{De cumulatie van privaatrechtelijke en strafrechtelijke gebiedsverboden}

Onder bepaalde omstandigheden is een cumulatie van sancties niet toegestaan. Zo blijkt uit artikel $68 \mathrm{Sr}$ dat '[b]ehoudens de gevallen waarin rechterlijke uitspraken voor herziening vatbaar zijn, (...) niemand andermaal [kan] worden vervolgd wegens een feit waarover te zijnen aanzien bij gewijsde van de rechter (...) onherroepelijk is beslist'. In deze bepaling is het ne bis in idem-beginsel neergelegd, maar het heeft geen werking ten aanzien van bestuursrechtelijke sancties. In dit verband moet evenwel worden gewezen op het bepaalde in artikel 5:44 lid 1 Awb. Het bestuursorgaan legt blijkens dit lid geen bestuurlijke boete op, indien tegen de overtreder wegens dezelfde gedraging een strafvervolging is ingesteld en het onderzoek ter terechtzitting is begonnen, dan wel een strafbeschikking is uitgevaardigd. Het spiegelbeeld van deze bepaling kan worden gevonden in artikel 243 lid 2 Sv. Deze una via-bepalingen zijn uitsluitend van toepassing op de cumulatie tussen de bestuurlijke boete en een strafrechtelijke sanctie. Beide zijn immers aan te merken als een 'criminal charge'.

Het bepaalde in artikel 5:44 Awb en artikel 243 lid 2 Sv is niet van toepassing op cumulatie tussen privaatrechtelijke en strafrechtelijke sancties. Een wettelijke regeling ontbreekt op dit gebied, waardoor het mogelijk is om ten aanzien van hetzelfde feit zowel een privaatrechtelijk als een strafrechtelijk gebiedsverbod op te leggen. Zo kan worden gedacht aan een persoon die zich schuldig heeft gemaakt aan openlijke geweldpleging in een horecagelegenheid en een collectieve horecaontzegging krijgt opgelegd van de horecaonderneming, maar eveneens strafrechtelijk wordt vervolgd ten aanzien van dit strafbare feit en 
wordt veroordeeld tot het betalen van een (deels voorwaardelijke) geldboete met als bijzondere voorwaarde dat de veroordeelde zich niet op of in de directe omgeving van een bepaalde locatie mag bevinden (art. 14c lid 2 onder $6 \mathrm{Sr}$ ). Een ander voorbeeld is de oplegging van een stadionverbod in combinatie met een oplegging van een strafrechtelijke vrijheidsbeperkende maatregel in de zin van artikel 38v Sr. De wetgever heeft in dit verband evenwel de verwachting uitgesproken dat de strafrechter niet snel een strafrechtelijk stadionverbod zal opleggen, indien reeds een privaatrechtelijk stadionverbod is opgelegd, omdat dit een volledige overlapping betekent. ${ }^{8}$ Onmogelijk is deze overlapping echter niet.

Wierenga en Brouwer vinden de cumulatie van privaatrechtelijke en strafrechtelijke sancties in het geval van de bestrijding van voetbalvandalisme problematisch en pleiten voor een terugkeer naar de centrale rol van het strafrecht. Over de ongewenste cumulatie merken zij het volgende op:

'De cumulatie van privaatrechtelijke en strafrechtelijke sancties in het huidige stelsel is in strijd met zowel het in het bestuurs- als het strafrecht gehanteerde uitgangspunt dat dubbele bestraffing zonder enige onderlinge afstemming achterwege dient te blijven. Dat uitgangspunt wordt geweld aangedaan als het gaat om een voetbalvandaal, omdat dan niet of nauwelijks rekening wordt gehouden met het evenredigheidsbeginsel.' Wierenga \& Brouwer 2014)

Met Wierenga en Brouwer kan worden ingestemd, indien sprake is van een cumulatie tussen een privaatrechtelijke bestraffende sanctie - zoals mogelijk de privaatrechtelijke geldboete - en een strafrechtelijke sanctie. Indien de privaatrechtelijke bestraffende sanctie wordt aangemerkt als een 'criminal charge', zou dit de weg naar een strafrechtelijke vervolging kunnen sluiten, hoewel een wettelijke regeling hiervoor thans ontbreekt.

Een punt van zorg is de informatie-uitwisseling tussen de ketenpartners in de geïntegreerde aanpak. Het strafprocesrecht faciliteert bijvoorbeeld het privaatrecht; concreet betekent dit dat het Openbaar Ministerie informatie deelt met de KNVB, op grond waarvan deze laatstgenoemde instantie privaatrechtelijke sancties oplegt. Bestaan 
voldoende waarborgen om te voorkomen dat met de stapeling van sancties, die het gevolg is van de uitwisseling van gegevens, een 'overreactie' ontstaat op hetzelfde feit, zo wordt afgevraagd (Van Rooij e.a. 2016, p. 818). Uit jurisprudentie blijkt dat cumulatie tussen privaatrechtelijke en strafrechtelijke sanctionering niet als problematisch wordt aangemerkt, omdat geen sprake is van twee bestraffende sancties van overheidswege, die worden opgelegd wegens hetzelfde feit. Om de evenredigheid van de opgelegde sancties niet uit het oog te verliezen, is de volgende gedachte opgeworpen:

'Zuiver gezien zijn private partijen zoals de KNVB en voetbalorganisaties niet gebonden aan het evenredigheidsbeginsel als beginsel van behoorlijk bestuur, maar de vraag kan worden opgeworpen of de actieve samenwerking van de KNVB met de overheid en de afstemming in beleidskaders en convenanten niet tot gevolg heeft dat alle betrokken partijen moeten streven naar een evenredig resultaat: niet alleen de wetgever, het bestuur en de rechter, maar ook de private ketenpartners die zich middels de convenanten hebben verbonden aan de publieke zaak.' (Van Rooij e.a. 2016, p. 818)

Hoewel deze gedachte aantrekkelijk is, moet deze kritisch worden bezien in het licht van het (controversiële) arrest van het EHRM inzake A. en B. tegen Noorwegen. ${ }^{9}$ In deze zaak is zowel een fiscale boete - een 'criminal charge' - als een (strafrechtelijke) vrijheidsstraf opgelegd voor hetzelfde feit. Er is dus sprake van een samenloop tussen een bestuurlijke bestraffende sanctie en een strafrechtelijke sanctie. In hoeverre is hier sprake van schending van het ne bis in idem-beginsel, zoals dit is neergelegd in artikel 4 van het Zevende Protocol bij het EVRM? Het EHRM oordeelt dat in casu geen sprake is van een schending van het ne bis in idem-beginsel, omdat beide procedures die leiden tot de bestraffende sancties een voldoende nauwe samenhang hebben, zowel inhoudelijk als in tijd. Deze procedures moeten op een voldoende samenhangende manier zijn gecombineerd, zodat zij een coherent geheel vormen. De volgende factoren spelen in dit verband een rol:

1. Dienen de verschillende procedures complementaire doelen?

2. Is de cumulatie van de procedures voorzienbaar?

9 EHRM 15 november 2016, $A B$ 2017/188, m.nt. T. Barkhuysen \& M.L. van Emmerik (A. en B./Noorwegen). 
3. Werken de verschillende betrokken autoriteiten samen en worden daarbij met name de verzameling van het bewijs en de beoordeling daarvan één keer verricht en gebruikt in beide procedures?

4. Is het totaalpakket aan sancties evenredig?

In casu was aan deze voorwaarden voldaan, waardoor de cumulatie tussen de bestraffende bestuurlijke sanctie en de strafrechtelijke sanctie geen strijd opleverde met het ne bis in idem-beginsel. Naar aanleiding van dit arrest heeft Hirsch Ballin betoogd dat ten aanzien van de cumulatie van sancties niet de vraag moet zijn of sprake is van een 'criminal charge', maar of sprake is van een coherent systeem waarbij de verschillende handhavings- en sanctioneringsmogelijkheden evenredig en op elkaar afgestemd zijn (Hirsch Ballin 2017). Op het eerste gezicht lijken dit arrest en het door Hirsch Ballin gegeven voorstel steun te geven aan de opgeworpen gedachte van Van Rooij e.a. (2016). Ten aanzien van de cumulatie tussen privaatrechtelijke en strafrechtelijke sanctionering dient te worden bezien of beide stelsels evenredig zijn en op elkaar zijn afgestemd, zodat sprake is van een coherent systeem. Op deze wijze dient het totaalpakket aan sancties, te weten de private en strafrechtelijke sanctie, evenredig te zijn aan de verweten gedraging.

Naar mijn mening dient een kanttekening te worden geplaatst bij deze uitleg. Een belangrijke beperking wordt namelijk gegeven door het bepaalde in artikel 4 van het Zevende Protocol bij het EVRM. Blijkens deze bepaling wordt niemand opnieuw berecht of gestraft in een strafrechtelijke procedure binnen de rechtsmacht van dezelfde staat voor een strafbaar feit waarvoor hij reeds onherroepelijk is vrijgesproken of veroordeeld overeenkomstig de wet en het strafprocesrecht van die staat. Met andere woorden: de uitleg van het EHRM over artikel 4 van het Zevende Protocol bij het EVRM is beperkt tot bestraffende sancties. Het privaatrechtelijke gebiedsverbod is niet aan te merken als een 'criminal charge', waardoor de vraag kan worden opgeworpen in hoeverre deze uitspraak van het EHRM ook toepasselijk is op de cumulatie tussen privaatrechtelijke en strafrechtelijke sancties. Met Van Rooij e.a. (2016) kan worden ingestemd dat het streven naar evenredige sanctionering aanbevelenswaardig is, maar naar het zich thans laat aanzien, kan dit niet worden 'afgedwongen'. Sterker nog: cumulatie tussen privaatrechtelijke en strafrechtelijke gebiedsverboden lijkt door 
het Openbaar Ministerie te worden onderschreven (Wierenga \& Brouwer 2014).

\section{Conclusie}

De integrale aanpak van misdaad heeft voordelen, maar er zijn ook belangrijke (rechtsbeschermende) nadelen. Bij de integrale aanpak van voetbalvandalisme en uitgaansgeweld is het mogelijk dat de KNVB respectievelijk de horecaondernemer(s) privaatrechtelijke sancties opleggen. Een van deze sancties is het gebiedsverbod. Zo kan de KNVB een persoon een stadionverbod opleggen wegens (vermoedelijk) gepleegde strafbare feiten. Horecaondernemers kunnen collectieve horecaontzeggingen opleggen, eveneens wegens (vermoedelijk) gepleegde strafbare feiten. Deze sancties worden niet aangemerkt als een 'criminal charge', waardoor de strafrechtelijke waarborgen van artikel 6 lid 2 en 3 EVRM niet van toepassing zijn. Het is vervolgens de vraag in hoeverre de oplegging van een stadionverbod of een collectieve horecaontzegging de oplegging van een strafrechtelijk gebiedsverbod in de weg staat. Blijkens jurisprudentie bestaan er geen belemmeringen om dergelijke sancties met elkaar te combineren. Hoewel er steeds meer aandacht wordt gevraagd voor de evenredigheid tussen de sancties, kan dit niet worden 'afgedwongen', omdat het privaatrechtelijke gebiedsverbod niet kan worden aangemerkt als een 'criminal charge'. Ik verwacht niet dat de Hoge Raad 'om' gaat en de oplegging van privaatrechtelijke gebiedsverboden als een 'criminal charge' zal gaan aanmerken. Evenmin verwacht ik dat het stadionverbod en de collectieve horecaontzegging door het EHRM als een 'criminal charge' zullen worden beschouwd. Dit laat onverlet dat het noodzakelijk is om de 'Straatsburgse' jurisprudentie in het vizier te houden, waarbij het de vraag is of de door het EHRM ingezette lijn van het arrest A. en B. tegen Noorwegen ook van toepassing wordt verklaard op de cumulatie tussen privaatrechtelijke en strafrechtelijke sancties. Thans moet de conclusie echter luiden dat weinig rechtsbescherming wordt geboden tegen een cumulatie van privaatrechtelijke en strafrechtelijke gebiedsverboden. Voorts geldt ten aanzien van de oplegging van een privaatrechtelijk gebiedsverbod niet de 'verhoogde' rechtsbescherming van artikel 6 lid 2 en 3 EVRM. Dit vloeit rechtstreeks voort uit het feit dat de (procedure tot) oplegging van privaat- 
rechtelijke gebiedsverboden niet zijn aan te merken als een 'criminal charge'. Indien een stadionverbod of een collectieve horecaontzegging is opgelegd, dient het Openbaar Ministerie terughoudend te zijn om ten aanzien van hetzelfde feit eveneens een gebiedsverbod te eisen.

\section{Literatuur}

\section{Adriaanse e.a. 2008}

P.C. Adriaanse, T. Barkhuysen, F.M.J. den Houdijker \& E.-J. Zippro, 'Het EVRM-kader voor invoering van punitive damages in mededingingszaken. Europese toestanden in het schadevergoedingsrecht?', Nederlands Tijdschrift voor Burgerlijk Recht 2008, p. 274-286.

\section{Albers 2002}

C.L.G.F.H. Albers, Rechtsbescherming bij bestuurlijke boeten.

Balanceren op een magische lijn? (diss. Maastricht), Den Haag: Sdu Uitgevers 2002.

\section{Bolt \& Lensing 1993}

AT. Bolt \& J.AW. Lensing, Privaatrechtelijke boete (Preadvies Nederlandse Vereniging voor Rechtsvergelijking), Deventer: Kluwer 1993.

\section{Brouwer \& Jacobs 2012}

J.G. Brouwer \& K. Jacobs, Naar een Engelse voetbalwet, Nederlands Juristenblad 2012, p. 1444-1450.

\section{Giesen 2015}

I. Giesen, 'Punitive damages: bestraffend en dus een "criminal charge”, maar wat dan?', Aansprakelijkheid, Verzekering \& Schade 2015, p. 145-146.

\section{'t Hart \& Foqué 1990}

A.C. 't Hart \& R. Foqué, Instrumentaliteit en rechtsbescherming; grondslagen van een strafrechtelijke waardendiscussie, Arnhem: Gouda Quint 1990.

\section{Hirsch Ballin 2017}

M. Hirsch Ballin, 'Strafrecht of bestuursrecht? Beide!', Blog Bestuursrecht 7 november 2017, https://blogbestuursrecht.nl.

\section{Van Rooij 2017}

A.E. van Rooij, Orde in het semipublieke domein. Particuliere en publiek-private orderegulering in juridisch perspectief (diss. Amsterdam VU), Den Haag: Boom juridisch 2017. 


\section{Van Rooij e.a. 2016}

A.E. van Rooij, J. Bijlsma, A.E.

Schilder \& J.L. Smeehuijzen, 'Bestrijding van voetbalgeweld. De civielrechtelijke, bestuursrechtelijke en strafrechtelijke aanpak van voetbalgeweld geïntegreerd beschouwd', Ars Aequi 2016, p. 809-819.

\section{Schuilenburg \& Van Steden}

2014

M. Schuilenburg \& R. van Steden, 'De Collectieve Horecaontzegging: uitsluiting uit de publieke ruimte?', Beleid en Maatschappij 2014, p. 4-18.

\section{Tops \& Schilders 2016}

P. Tops \& H. Schilders, 'Naar een meervoudige aanpak van ondermijning', Tijdschrift voor de Politie 2016, p. 12-15.

\section{Van der Vorm 2017}

B. van der Vorm, 'Strafrechtelijke gebiedsverboden ter handhaving van de openbare orde', Delikt en Delinkwent 2017, p. 344-360.

\section{Wierenga \& Brouwer 2014}

A.J. Wierenga \& J.G. Brouwer, 'Dubbelrol OM bij bestrijden voetbalvandalisme. Over doorkruising van publiekrecht', Jurisprudentie Bestuursrecht Plus 2014, p. 244-255. 